\title{
Ultra-fast Consolidator Machine Development Individualized Mass Production of Thermoplastic Tailored Blanks based on Laser-assisted Tape Placement with in-situ Consolidation
}

\author{
M. Emonts ${ }^{1)}$, K. Fischer ${ }^{1)}$, A. Peitz ${ }^{1)}$, T. Weiler ${ }^{2)}$ \\ 1) AZL Aachen Center for Integrative Lightweight Production (AZL) of RWTH Aachen University, \\ Aachen, Germany \\ 2) Conbility $\mathrm{GmbH}$, Aachen, Germany
}

\section{Keywords}

In-Situ Consolidation, Laser-Assisted, Tape placement, Tape processing, Thermoplastic Tapes, Ultrafast Consolidator Machine

\begin{abstract}
The new Ultra-Fast Consolidator Machine development offers both high flexibility and mass production of tailored thermoplastic laminates with reduced scrap. The machine system can be configurated to achieve fully consolidated multi-layer laminates with different fiber directions and minimized scrap (thermoplastic tailored blanks) produced in cycle times below 5 seconds. This individualized mass production is accomplished by a combination of laser-assisted tape placement with in-situ consolidation and a piece-flow principle, which is state of the art in the printing industry but has not been used in such a way within composite production. The achievable productivity is enhanced to more than $500 \mathrm{~kg} / \mathrm{hour}$ by this piece-flow principle with carriers moved through multiple application stations which are equipped with multiple tape placement applicators. The new machine is scalable: multiple application stations can be added, e.g. for each layer one station for mass production or for each fiber direction one station with a carrier-conveyor carousel: here the carriers are moved multiple times through the application stations.

This innovative machine system is a result of an 18-months AZL Joint Partner Project, conducted in 2017-2018 by the research partners AZL Aachen and Fraunhofer IPT Aachen, in cooperation with 12 industrial partner companies including Conbility, Covestro, Engel, Evonik, Fagor Arrasate, Faurecia SE, Laserline, Mitsui Chemicals, Mubea Carbo Tech, Philips Photonics, SSDT and Toyota (in alphabetical order). The system won the international JEC Innovation AWARD 2019 in the category "Industry \& Equipment".
\end{abstract}

\section{Introduction}

The use of fiber-reinforced composite materials can enhance part stability and strength substantially, while simultaneously reducing weight, material usage and geometric complexity. Fiber-reinforced thermoplastic materials offer further potential due to their very high strength to weight ratio, excellent fatigue and fracture resistance, recyclability and their potential for fast process cycles [1,2].

Thermoplastic tailored blanks have been adopted as a highly productive, low scrap rate mechanism for load-optimized part production [3]. However, CFRP parts are still mainly produced using textile preforms, inducing high scrap rates. With carbon fiber prices being high, this in turn results in high material cost. By using tailored blanks, production rates can be optimized and hence part costs minimized.

Current systems for tailored blank production lack in productivity and throughput potential. Especially robot-based systems show lower efficiency and lower placement rates in terms of $\mathrm{kg} / \mathrm{h}$, while inducing high machine investment costs [4].

The presented, highly productive machine concept for thermoplastic tailored blank production offers a new range of possibilities for mass production of e.g. consumer goods such as laptop backcovers or 
transport boxes. The produced laminates can be used as stiffening structures in combination with highvolume injection moulding processes, enabling part numbers in the millions with considerably less material costs, due to e.g. elimination of injection-moulded stiffening ribs [2,5].

The new machine concept can be scaled up: multiple applicator stations can be added, e.g. forming a production street with one station per laminate layer for mass production, or one station per fiber direction in combination with a carrier-conveyor carousel where carriers are fed multiple times through the applicator stations.

This configurable and scalable machine concept opens up new possibilities for tape producers as well, regarding forward integration of their business models: tape manufacturers are now enabled to produce and sell not only their tapes but also tailored laminates by individual mass production.

This paper will present related work and current tape-placement systems in Section 2. In Section 3, the new machine concepts and methods will be presented. Section 4 will present machine and laminate results. Finally, a conclusion will be given, ending in an overview of further required work.

\section{Related Work}

\subsection{Current Tape-placement Systems}

Current tape placement and tape winding systems are dominated by manipulator-based systems which use movable placement heads over a fixed placement surface. This surface can either be flat or curved, depending on the application. As of today, these systems represent the majority of commercially available tape placement systems [6]. Usually, these systems employ gantries or multi-axis robots. They possess a high geometric flexibility but are limited in throughput, due to sequential tape application and lower efficiency [7].

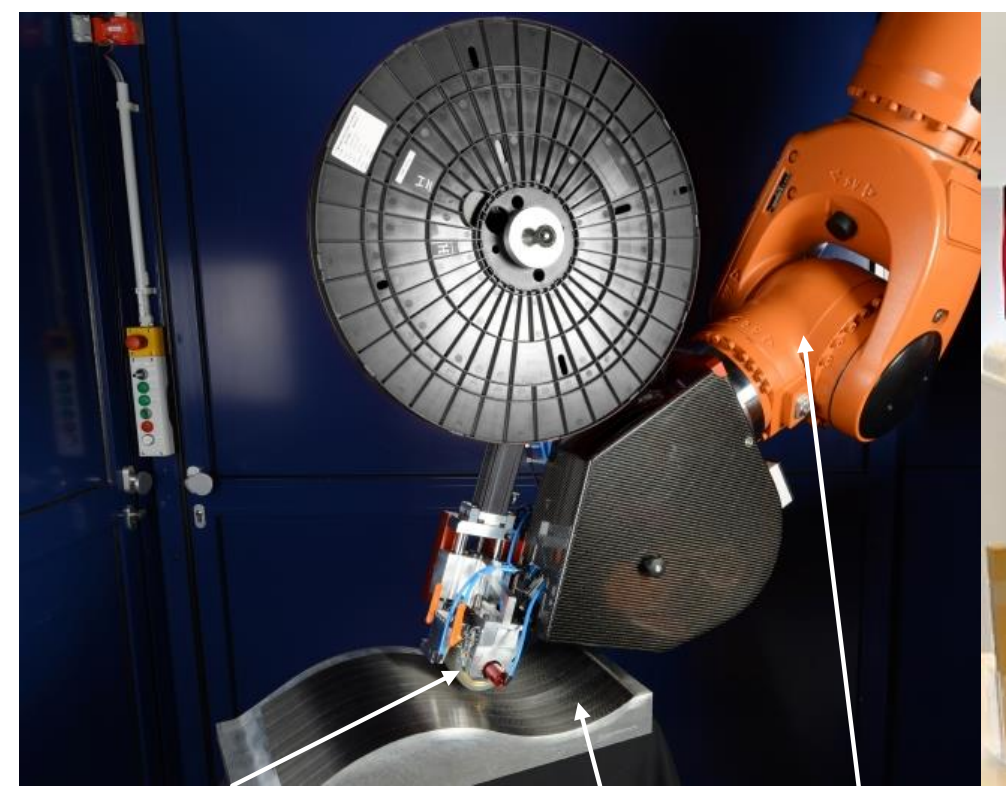

Consolidation Roller

Placed Tape Multi-axis Robot

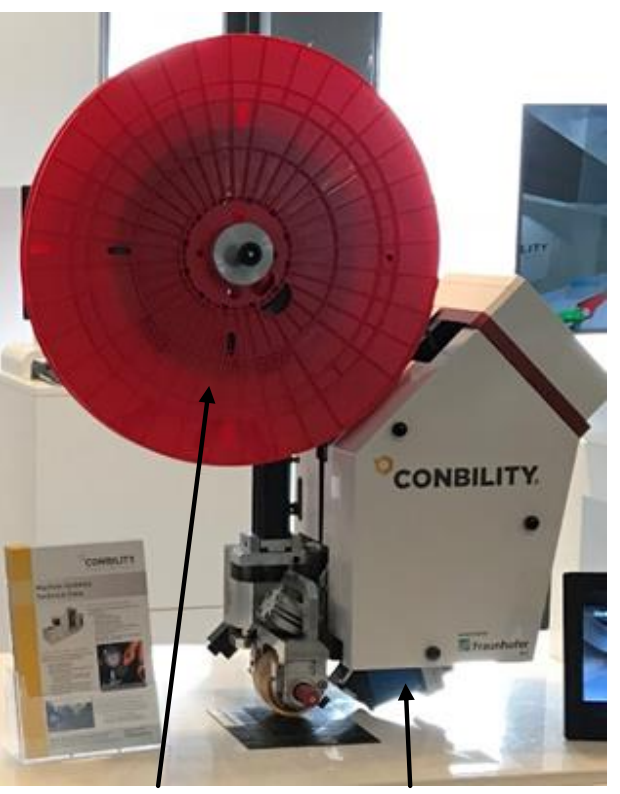

Tape Spool

Heat Source

Figure 1: Manipulator-based Tape Placement System PrePro 3D of Fraunhofer IPT (left), commercialized by Conbility GmbH (right) [8]

Systems with higher efficiency and throughput employ a moveable placement surface, usually in form of a rotary table with sometimes additional degrees of freedom. This splits required movements onto multiple subsystems, accelerating the process $[9,10]$. 


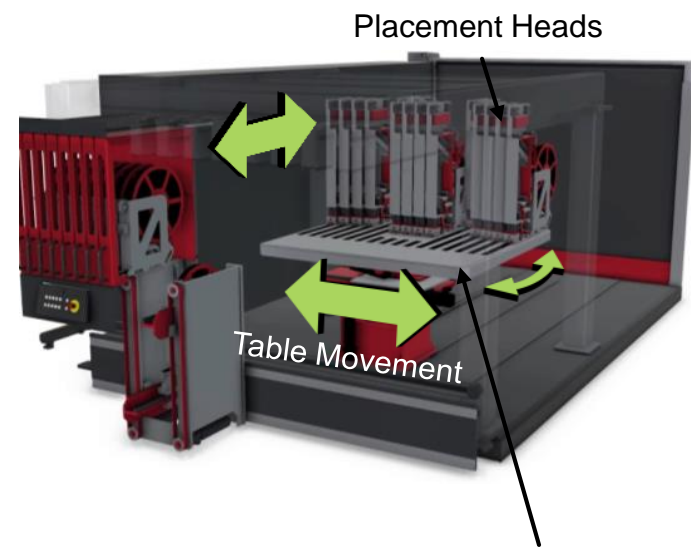

Rotary Table
Placement Heads

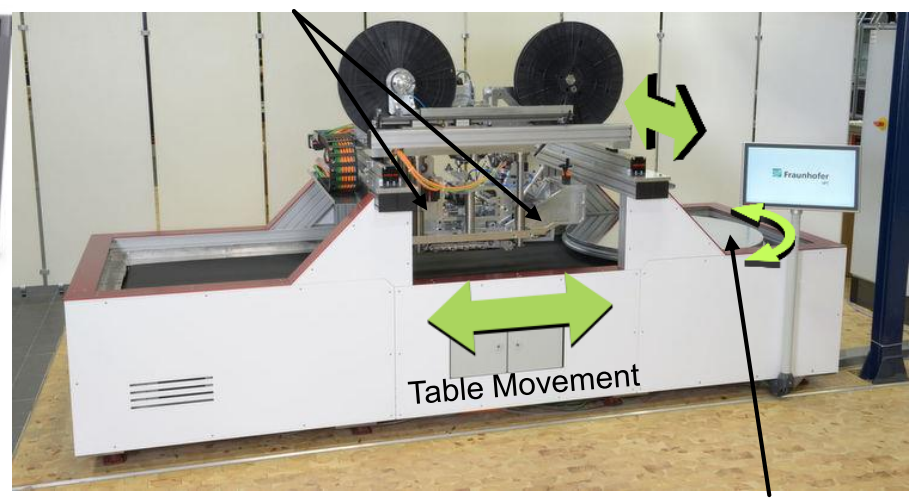

Rotary Table

Figure 2: Active-Table based Tape Placement Systems FILL Multilayer (left) and PrePro 2D from

Fraunhofer IPT and Conbility GmbH (right) $[8,9]$

Full consolidation of laminates during the placement process is designated as in-situ consolidation. This eliminates the otherwise necessary process step of post-consolidation using compression-moulding presses and thus enabling thickness variations in laminates.

Figure 3 schematically shows the process of in-situ consolidated tape placement. As of today, most tape placement systems are not able to achieve in-situ consolidation at high speeds, but employ local tacking of laminates using e.g. ultrasonic sonotrodes [9-11].

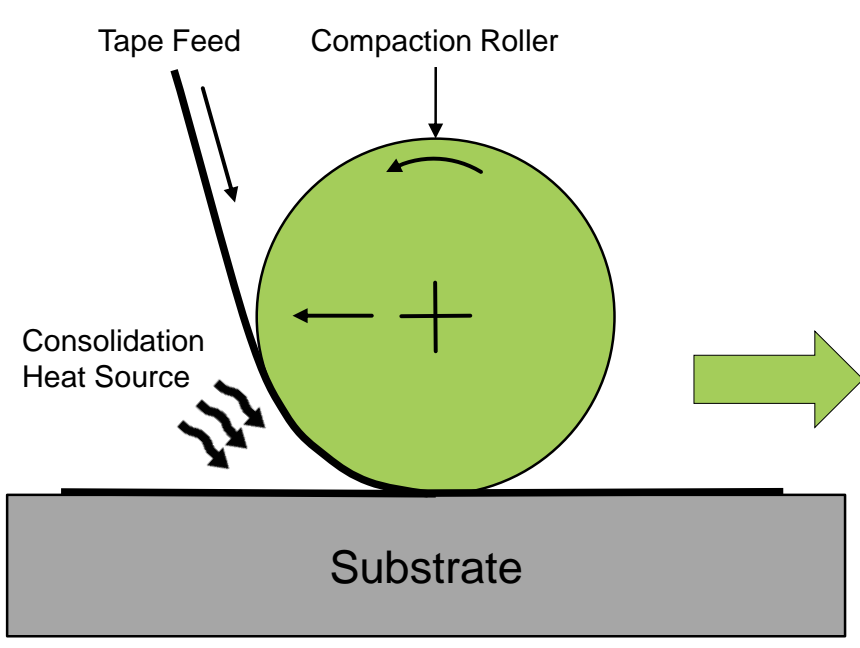

In-situ consolidation:

- No additional process steps

- Thickness variations

- Waste reduction

- Energy efficiency

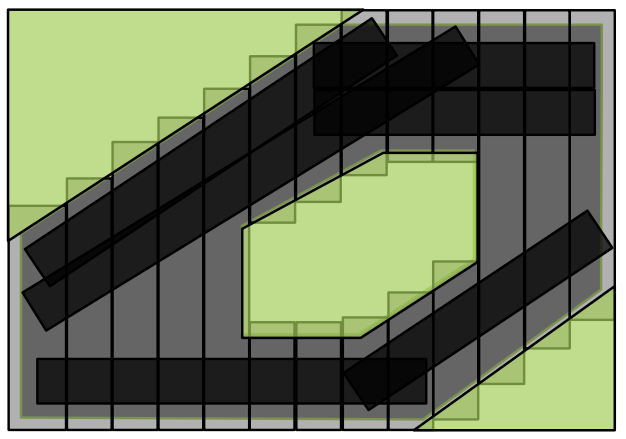

Figure 3: In-situ Consolidation using Compaction Roller Strategy

For achieving competitive in-situ consolidation, high energy-density systems for tape heating such as Infrared or laser sources have been employed successfully. Especially laser systems realize high intensities and possess low reaction times in the milliseconds range. This enables fast and reliable process control $[12,13]$.

\subsection{Industrial Piece-flow based Production}

To increase productivity in tape placement systems, highly productive industries such as the printing and the labelling industry were analyzed. These systems follow a piece-flow approach, where parts are circulated through production streets at high velocities. Acceleration and deceleration can be kept high due to low moving masses of the parts. 
Upon closer inspection, an analogy to the technological development was found between the printing industry and the tape placement industry, see Figure 4 . There, it can be seen that the final step, moving from active-table based systems to piece-flow systems has yet to be realized in tape placement.

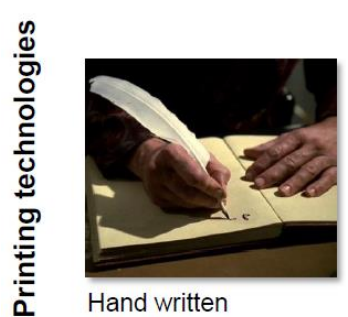

Hand written

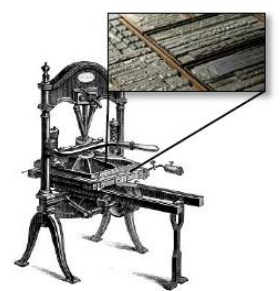

Letterpress

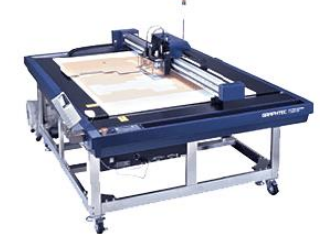

Flat bed plotter

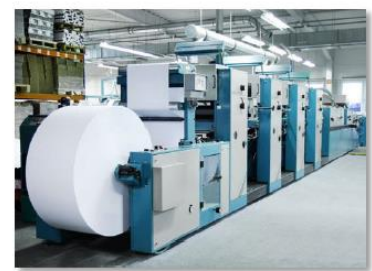

High-speed printing systems

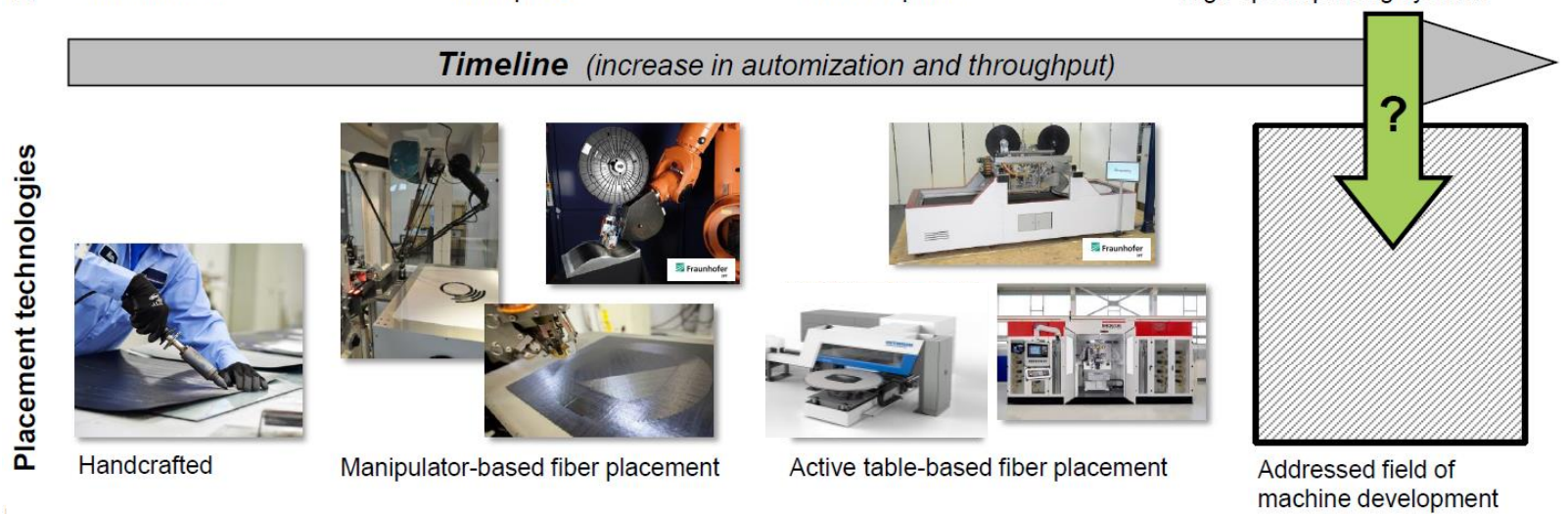

Figure 4: Development of Printing Technologies in comparison to Tape Placement $[8,9,10,14,15]$

This technological production concept was the motivation for the proposed tape placement system. In the following, the corresponding machine concept and technology will be described.

\section{Concepts and Methods}

\subsection{General Machine Principle}

The presented system builds on fixed manipulators during application and a moving carrier/laminate system feasible for realizing different fiber angle orientations. This concept leaves flexibility for designing the machine, since the production street can be adapted to production needs e.g. by scaling up for mass production. A central conveying system transports laminate carriers, feeding these through application stations where tape is laid down by one or multiple tape placement heads, called applicators in the following. An exemplary production street configuration can be seen in Figure 5. 


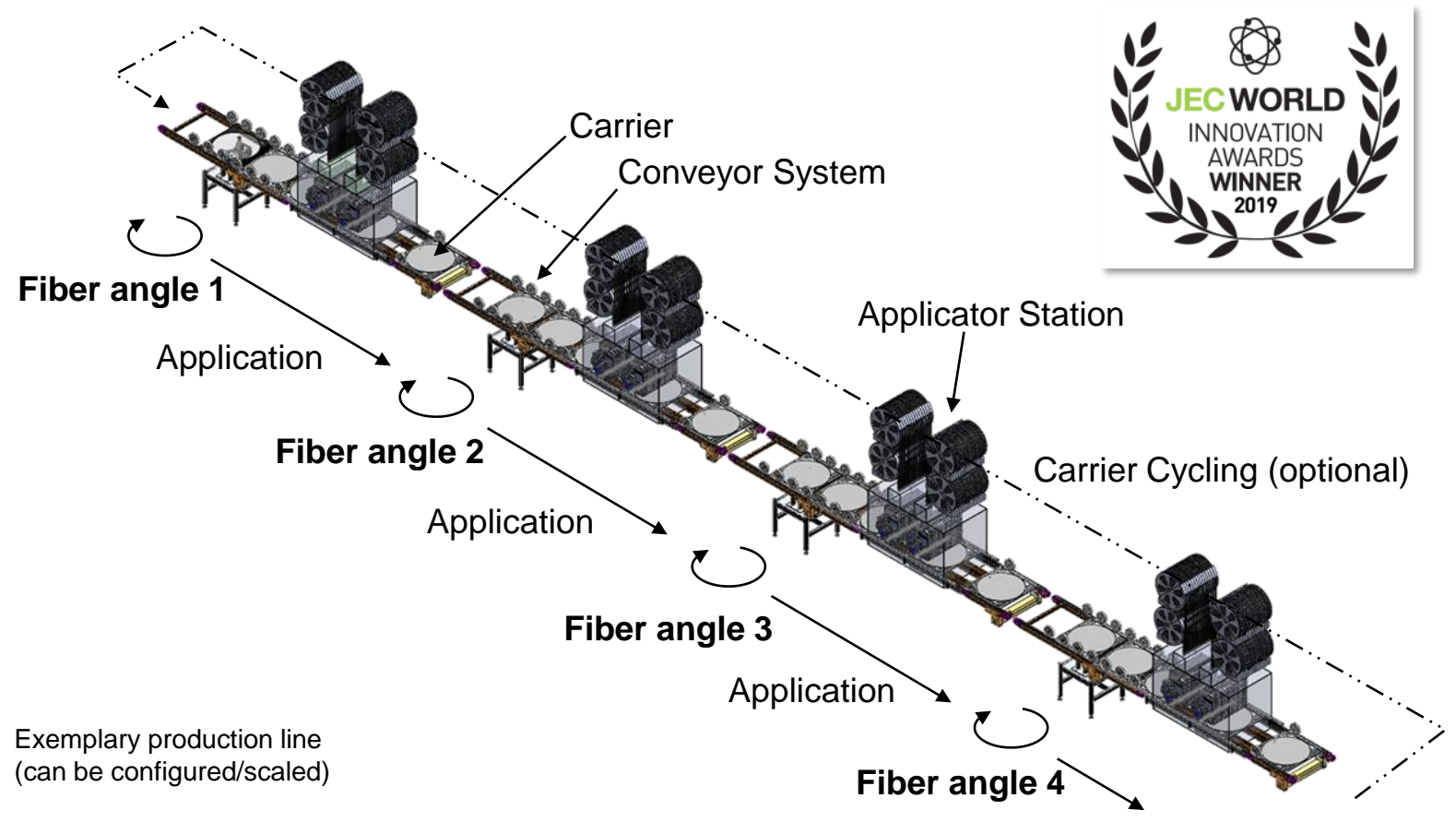

Figure 5: Piece-flow Production Concept

The proposed machine prototype achieves placement speeds up to $1 \mathrm{~m} / \mathrm{s}$ and can be upscaled to achieve cycle times under $4 \mathrm{~s}$ per finished blank. Each individual station can be equipped with up to 28 applicators including laser sources, producing laminates of $700 \mathrm{~mm}$ width. The Prototype system can be seen in Figure 6 . Due to the static laser zone during process, machine dimensions can be kept to a minimum, resulting in station dimensions of $4.6 \mathrm{~m} \times 1.1 \mathrm{~m} \times 2.8 \mathrm{~m}(\mathrm{l} \times \mathrm{w} \times \mathrm{h})$.

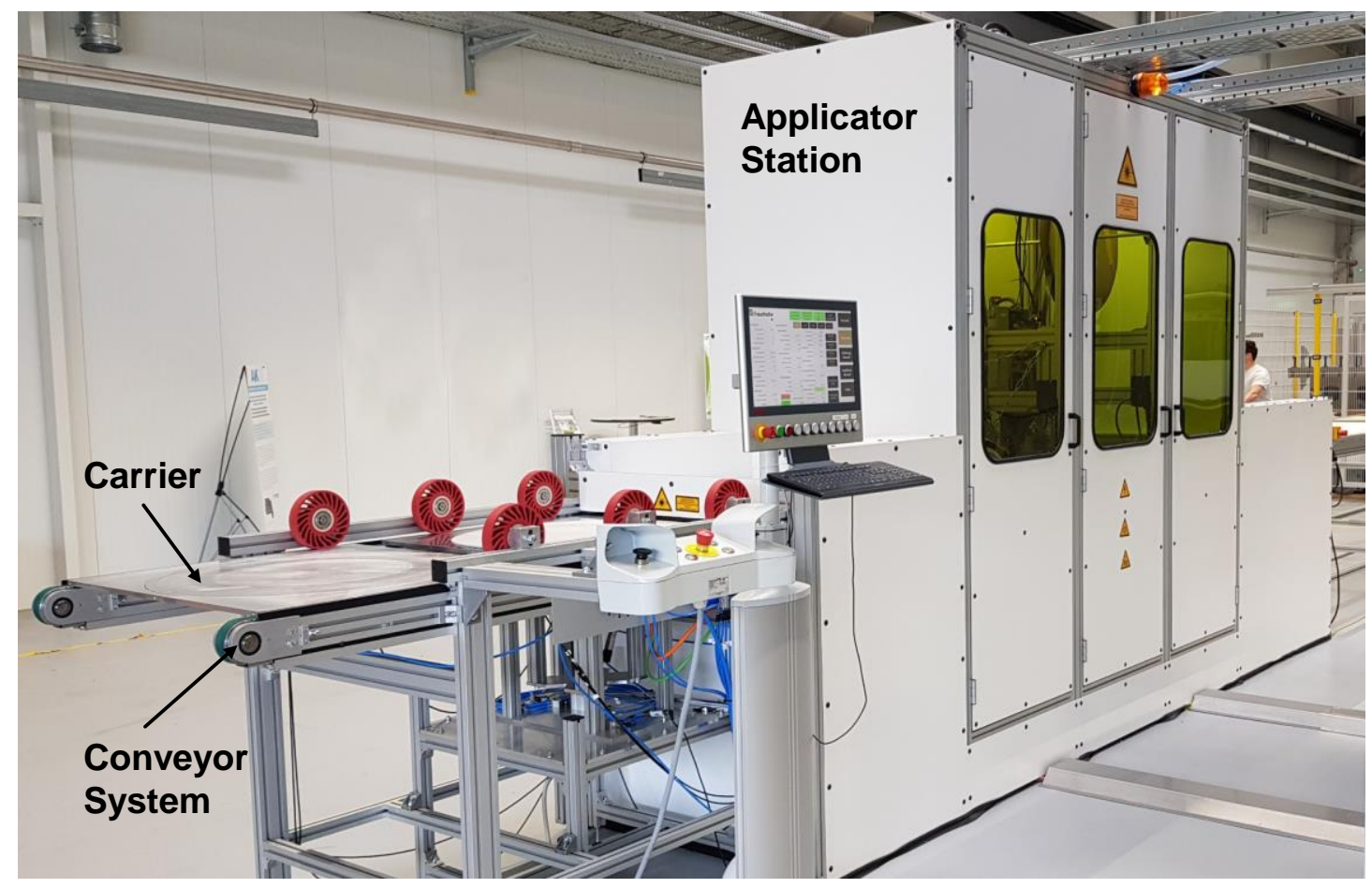

Figure 6: Ultra-Fast Consolidator Machine Prototype at AZL with one Applicator Station 
The designed applicator station was developed under a custom laser-safety concept, enabling fully laser-safe operation without any additional safety infrastructure. The concept was designed so that inbound and outbound carriers can circulate freely even during active laser operation. This design was subject to a thorough laser safety inspection by external experts and was found to be operable in laser safety class 1.

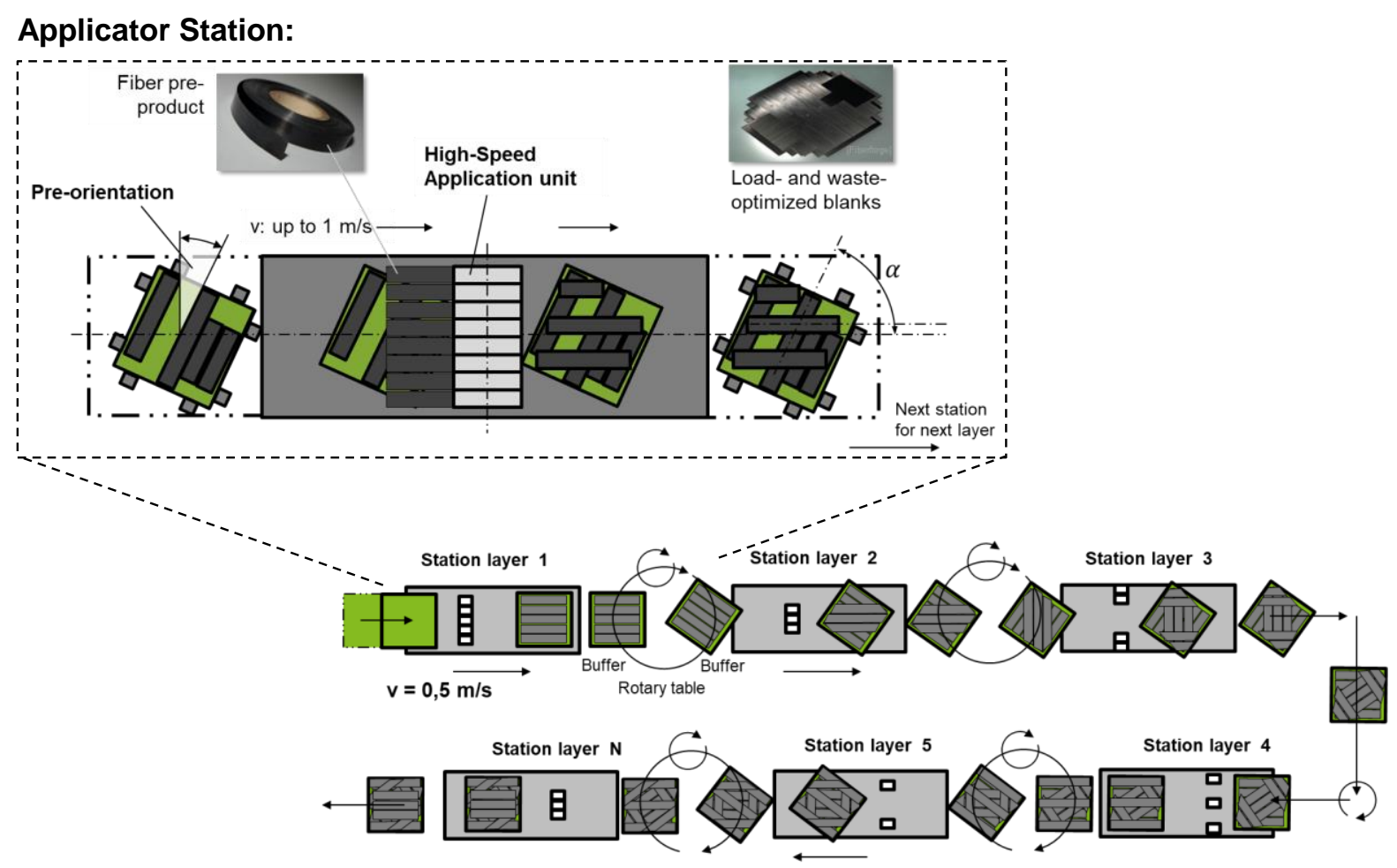

Figure 7: Overview of an Applicator Station inside a Production Line

Figure 7 gives an overview of the tape laying process inside each applicator station. The station possesses multiple, parallel applicators which place tapes on a moving substrate carrier. Next, carriers are oriented in regard to the fibre angle, before the next, complete layer is laid down using a possibly different applicator configuration. This can be scaled up as needed, or a carrier feedback carousel can be used for returning carriers to the first station. The following Section will describe the applicator station more in detail.

\subsection{Applicator Station}

The key component to the proposed fiber placement machine is the specifically developed tape application head, called applicator.

The proposed machine concept includes high-speed tape application with highly parallelized applicator heads and full in-situ consolidation of laminates, while applicators are static and carriers are mobile. Therefore, the application station is equipped with fast-moving linear axes.

Applicator width was kept to a minimum of $50 \mathrm{~mm}$. Tapes of $25 \mathrm{~mm}$ width are used, which results in a $50 \mathrm{~mm}$ pitch in between Tapes. Therefore, two applicator rows have to be placed in a shifted cascade to permit gap-free tape placement, see Figure 8.

Each cascade has to be accommodated into the $800 \mathrm{~mm}$ machine grid, resulting in a length of $1600 \mathrm{~mm}$ for the actual application zone. Multiple technical solutions were integrated for precise tape guidance, tape feeding and consolidation. 


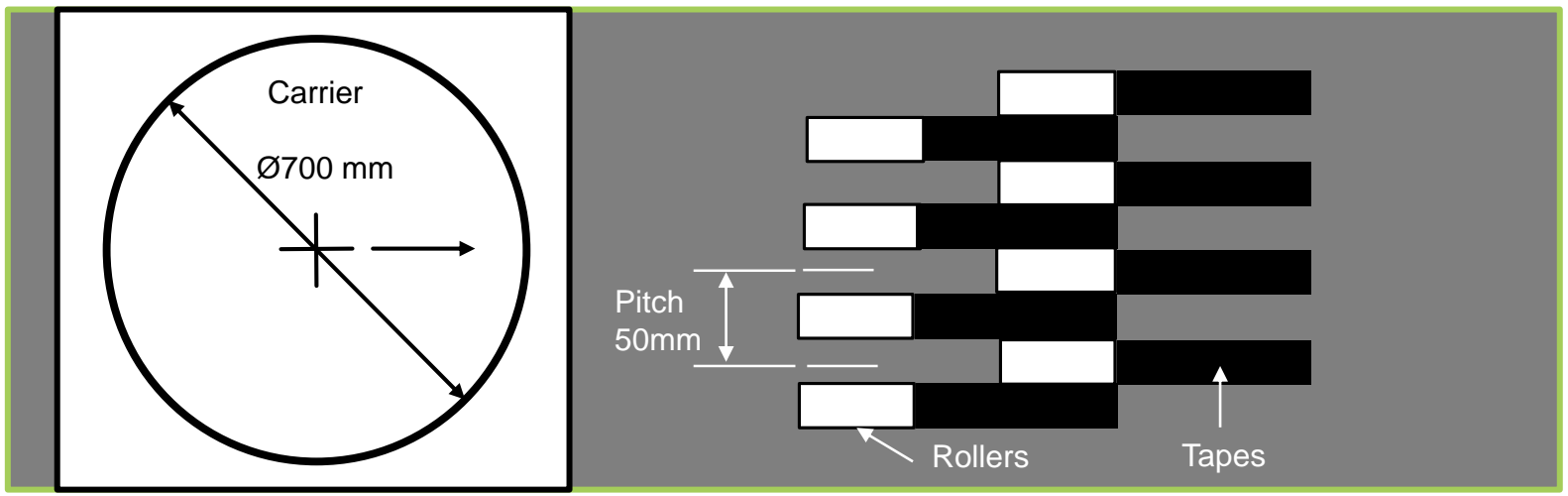

Figure 8: Application Zone Design with Dual Cascade

Applicator design underlies one main requirement: maximum width of $50 \mathrm{~mm}$. This poses some technical challenges. Figure 8 shows the integration of an applicator inside the applicator station.

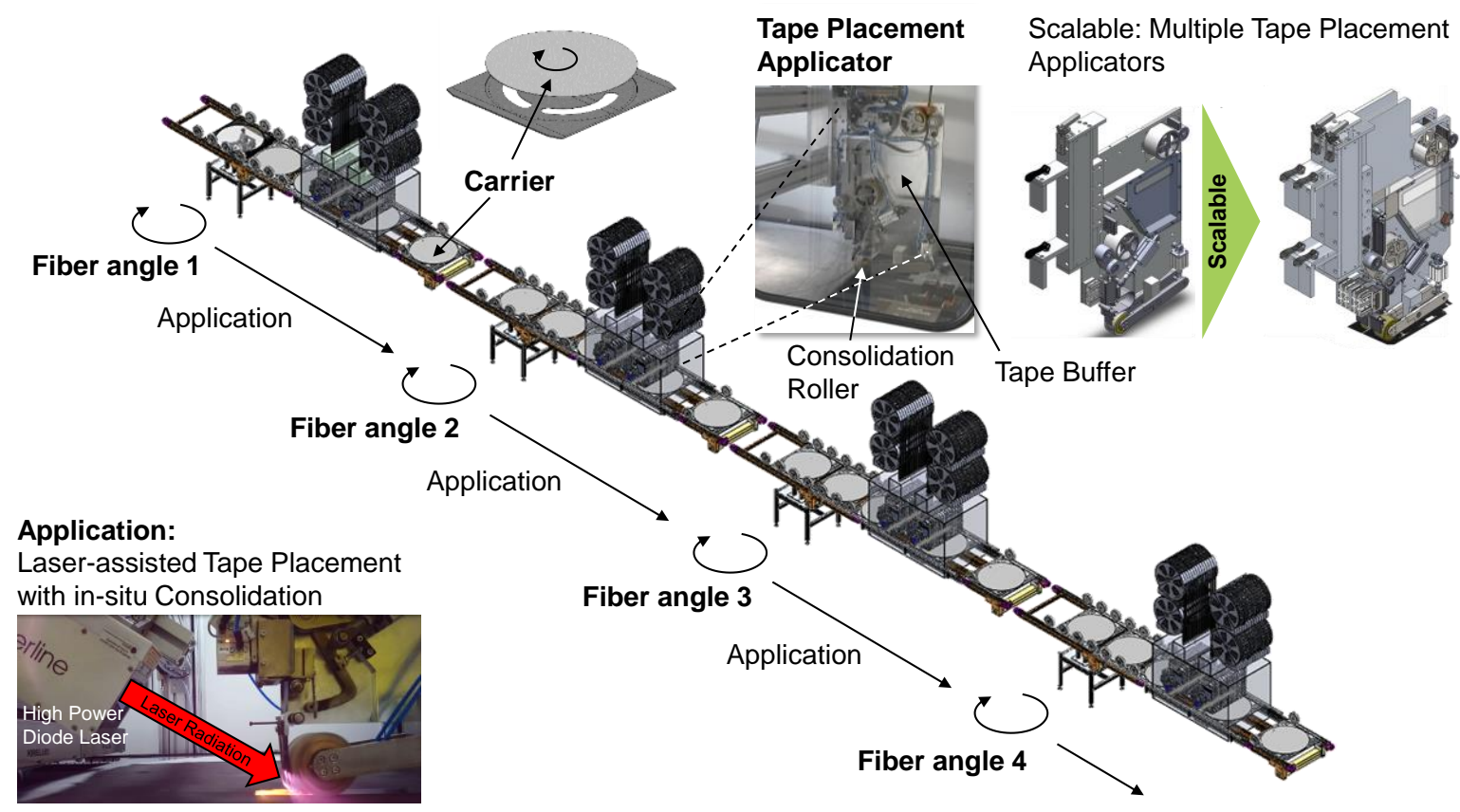

Figure 9: Applicator Design

To enable reproducible tape placement and minimize inertia due to spool weight, pulling tape from the spool and feeding it under the consolidation roller needs to be decoupled. For this purpose, tape is first guided through a buffer. This buffer is sensor-controlled to enable automated filling.

Due to continuously moving carriers during application, tape cutting has to be done on-the-fly. This poses some serious challenges due to the high movement speeds of up to $1 \mathrm{~m} / \mathrm{s}$. Two high-speed knives are used to cut the tape continuously from the side.

Cutting at high movement speeds resulted in the formation of tape bulges over the blades during cutting due to mechanical delays of the pneumatic actuators. To resolve this effect, a cutting buffer was incorporated after the cutting mechanism. The buffer is mechanically coupled to the feed drive's counterroller.

For heat generation, each applicator requires one laser source. Here, two narrow laser sources were tested and used successfully: The direct diode laser LDMDirect2500 from Laserline, with an output 
power of $2.5 \mathrm{~kW}$ and a wavelength of also $980 \mathrm{~nm}$, and the Philips VCSEL PPM417, a vertical cavity surface emitting laser in the short infrared wavelength spectrum at $980 \mathrm{~nm}$, with an output power of $2 \mathrm{~kW}$. Both laser heads do not exceed the $50 \mathrm{~mm}$ width limit defined for the applicator and are therefore suitable for integration into future serial machines.

\subsection{Conveyor System}

Building on the piece-flow concepts, the actual conveying technologies had to be defined. Main factors for decision of the system to employ were:

- Maximum speed

- Accuracy of positioning

- Maximum load capacity

- Scalability and extensibility

Considering these requirements, two systems were selected for conveying. Inside the application zone, a linear pusherdog system has been employed. For conveying carriers to and from the application zone, a conveyor belt system is used. Both systems fulfil maximum speed requirements of $1 \mathrm{~m} / \mathrm{s}$.

In terms of accuracy, pusherdog scores high, in part due to slip-free conveying. On conveyor belts, carriers can slip, resulting in lower accuracy. To compensate for slip, inductive carrier sensors and stopping units against which carriers are conveyed for repeatable positioning are employed. Furthermore, elastic counter rollers are used for increasing friction from carriers to the belt and hence minimize slip.

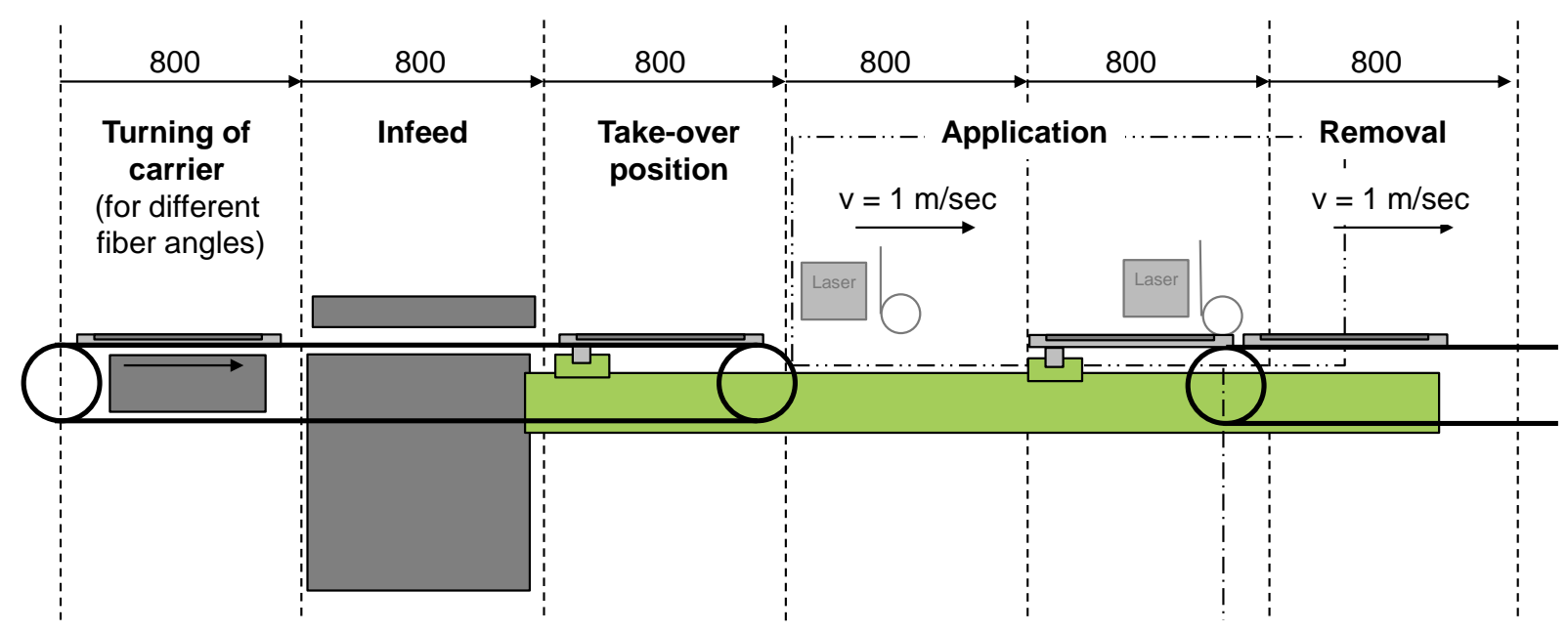

Figure 10: Machine Grid for Conveying and Application in one Station

Due to the modular machine concept, the transport system also needs to follow a modular design. This emphasizes the use of conveyor belts in between application stations, since they can be placed adjacent to each other, easily handing over carriers. See Figure 10 for the modular, station-based conveying design.

In the current setup, four grid stations are present before the application zone and one after application. The four entry stations include a buffer station (not represented here), an orientation station, a lasersafe entry tunnel station and an overtake station to the application zone, with optional pre-heating. The first buffer station serves as a manual carrier input station and can be omitted in subsequent stations or in fully automated systems. The orientation station permits fiber angle orientation of the laminate prior to tape application, through turning of a round inlet of the carrier. After the application zone, a laser-safe exit tunnel with a conveyor belt transports the carriers out of the laser-safe application zone.

An $800 \mathrm{~mm}$ grid was chosen, resulting in smaller carriers of $735 \mathrm{~mm}$ length. Accounting for acceleration, deceleration and maximum movement speed of $1 \mathrm{~m} / \mathrm{s}$, total conveying time per cycle amounts to $1.2 \mathrm{~s}$. 


\subsection{Modularity of the configurable Production System}

The presented production concept is based on a modular design. Each individual station can possess any flexible number of applicators in adapted layup configurations. Applicators can be repositioned perpendicular to the carrier movement direction in between production processes. Furthermore, applicator stations and conveying system are modularly designed, so that production streets can easily be configured and scaled up to suit the processes' needs. The station number is flexible and carrier feedback loops can be integrated.

Scenario 1
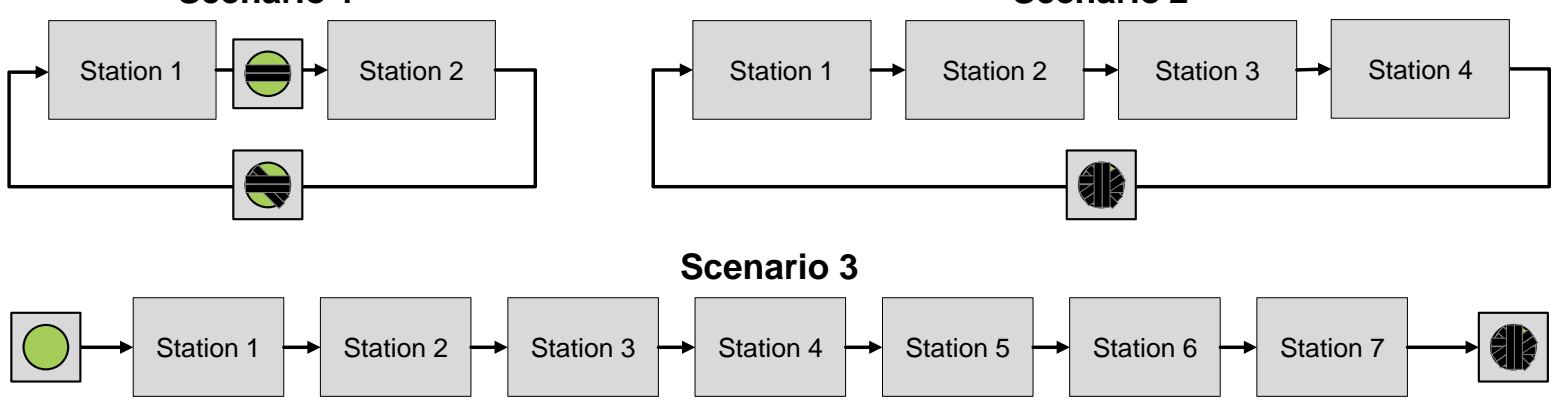

\section{Scenario 2}

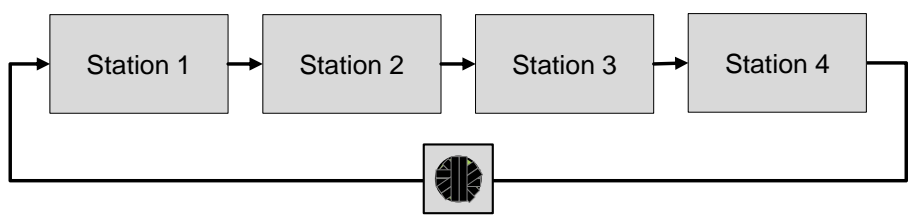

Scenario 3

stion 4

Figure 11: Different Production Scenarios for Laminate Manufacturing

This results in realization of different production scenarios. Maximum production flexibility can be achieved by using only one or two stations and integrating a carrier feedback loop (scenario 1, Figure 11). This scenario requires the lowest investment cost and is suitable for low-volume production and high part variability. Here, cycle times per laminate and machine downtimes rise with every additional layer.

Another possible, optimized production street configuration builds on having one station per fiber angle of the laminate (scenario 2, Figure 11). Here again, a feedback loop is integrated into the system, so that multiple layers with identical fiber angle orientation can be laid down. This increases productivity and decreases cycle times compared to scenario 1 but increases investment costs for the machine.

The most productive but least flexible scenario (scenario 3, Figure 11) includes one station per laminate layer and does not include a feedback loop. Each station is equipped with the according number of applicators to lay down each layer in one pass. Here, lowest cycle times, under $5 \mathrm{~s}$ per laminate can be achieved. No applicator repositioning is required, minimizing machine downtimes. On the other hand, part variations and production of new laminate types require a higher modification effort and total investment cost is highest here.

The station and machine modularity permits easy upscaling from each scenario to higher-productivity scenarios. Scenario 3 can then again be easily up scaled by adding more stations to the production line.

\section{Results}

The overall machine setup was found to fulfil placement speed and cycle time requirements. For evaluation of the placement process, two demonstrator laminates were manufactured, see Figure 12. One is made out of PC/CF Tape with $0.15 \mathrm{~mm}$ thickness, produced at $500 \mathrm{~mm} / \mathrm{s}$ placement speed. The second laminate is a PP/CF tape with $0.15 \mathrm{~mm}$ thickness, produced at $500 \mathrm{~mm} / \mathrm{s}$. Both laminates consist of 6 layers. 


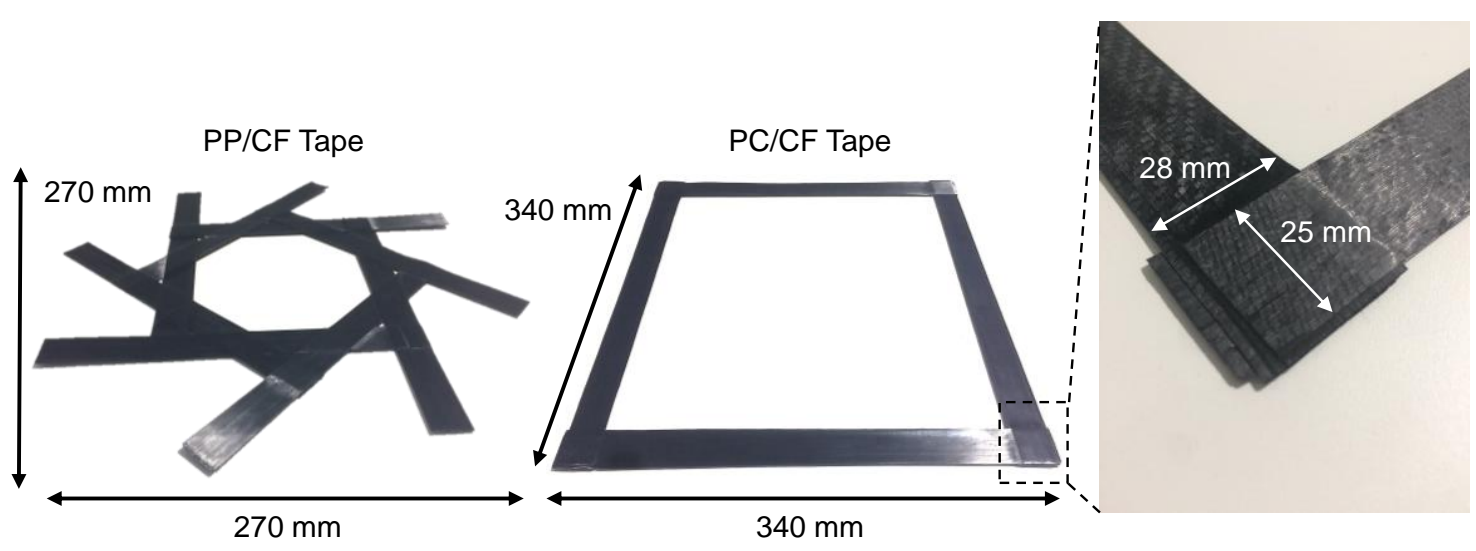

Figure 12: Produced Laminate Demonstrators with achieved Placement Precision

Furthermore, in-situ consolidation was validated. PP-CF tapes could be fully consolidated with process speeds up to $850 \mathrm{~mm} / \mathrm{s}$ using current lasers. PC-CF tapes required more laser power, reaching in-situ consolidation at speeds up to $500 \mathrm{~mm} / \mathrm{s}$.

Finally, micro sections of laminates were done and void content was visually evaluated. The results can be seen in Figure 13. In accordance with industrial experts, it was found that void content was acceptably low. Further work will need to address an in-detail, qualitative characterisation of laminates.

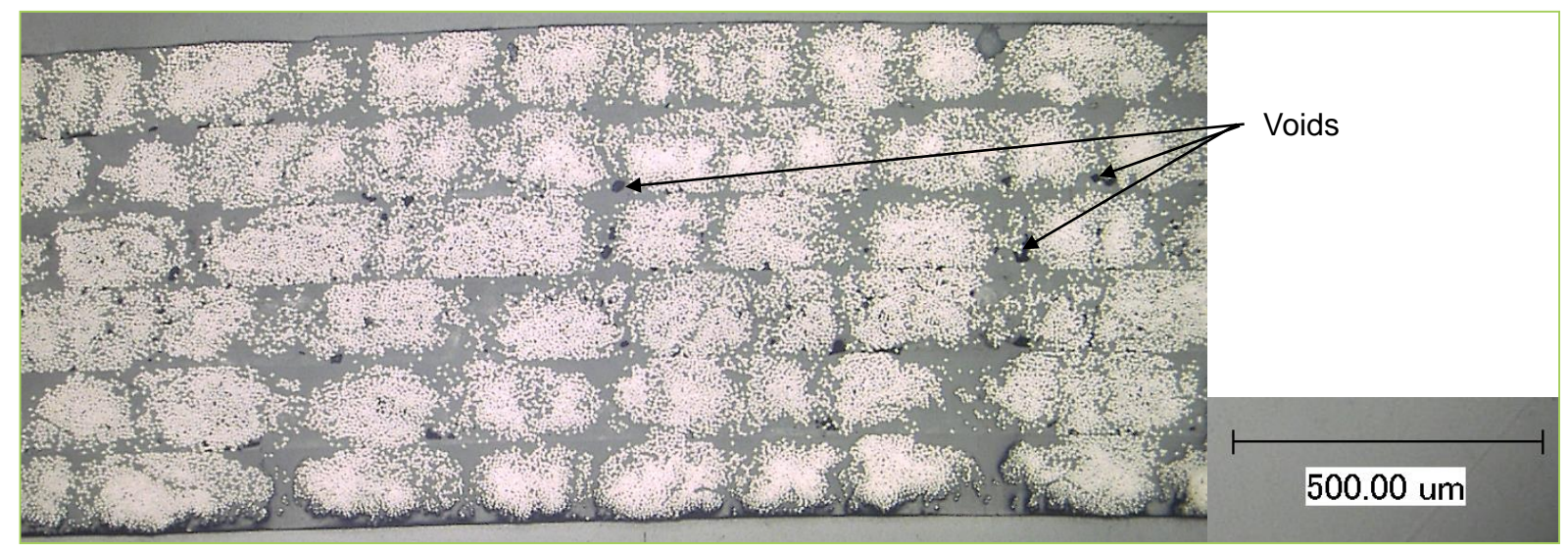

Figure 13: Void Content inside produced Demonstrators

\section{Discussion and conclusion}

This paper presents a new concept for automated tape placement machinery. The Ultra Fast Consolidator Machine concept follows a piece-flow approach, significantly reducing moving masses and hence increasing movement speeds, resulting in low cycle times. Fixed tape application heads place the tapes onto circulating carriers, either in an open production street or in a closed process loop, depending on part numbers and required production flexibility. The machine is designed as a modular, configurable system, permitting easy scaling.

Carrier conveying permits placement speeds of up to $1 \mathrm{~m} / \mathrm{s}$, representing the current technological limit for in-situ consolidation speeds. Heating is achieved using two different, narrow laser sources of $2 \mathrm{~kW}$ and $2.5 \mathrm{~kW}$ power. Both laser sources possess a rectangular laser spot, heating both incoming tape and the substrate. Further work needs to address characterisation of process parameters and maximum processing speeds depending on materials used. Mechanical properties of manufactured laminates will also have to be tested in detail. 
Applicators were limited to a maximum width of $50 \mathrm{~mm}$. This permits the use of a double cascade of applicators for gapless placing of one tape layer per station. Placement precision was found to be $\pm 3.5 \mathrm{~mm}$ in process ( $\mathrm{x}$-) direction and $\pm 1.5 \mathrm{~mm}$ in $y$-direction. In the future, placement precision optimization will be investigated.

Finally, for full conceptual testing, a feedback loop and a second station need to be built up. These also need to be used for investigating thermal management over the whole process chain.

\section{References}

[1] Ghori, S.W.;Siakeng, R.; Rasheed, M.; Saba, N.; Jawaid, M.: The role of advanced polymer materials in aerospace. In: Jawaid, M. (ed); Thariq, M. (ed). Sustainable Composites for Aerospace Applications. Duxford Woodhead: Elsevier Science, 2018, pp. 19-34.

[2] Brecher, C.; Kermer-Meyer, A.; Janssen, H.; Werner, D.; Emonts, M.: Economic production of load-optimized thermoplastic composites. In: JEC Composites Magazine. 50. Jg., 2013.

[3] Pallett, R.J.; Lark, R.J.: The use of tailored blanks in the manufacture of construction components. In: Journal of Materials Processing Technology. 117. Jg., 2001, 1-2, P. 249-254.

[4] Janssen, H.; Peters, T.; Brecher, C.: Efficient Production of Tailored Structural Thermoplastic Composite Parts by Combining Tape Placement and 3d Printing. In: Procedia CIRP. 66. Jg., 2017, P. 91-95.

[5] Brecher, C.; Schmitt, R.; Lindner, F.; Peters, T.; Emonts, M.; Böckmann, M. G.: Increasing Cost and Eco Efficiency for Selective Tape Placement and Forming by Adaptive Process Design. In: Procedia CIRP. 57. Jg., 2016, P. 769-774.

[6] Szcesny, M.; Heieck, F.; Carosella, S.; Middendorf, P.; Sehrschön, H.; Schneiderbauer, M.: The advanced ply placement process - an innovative direct 3D placement technology for plies and tapes. In: Advanced Manufacturing: Polymer \& Composites Science. 3. Jg., 2017, Nr. 1, P. 2-9.

[7] Brecher, C; Emonts, M.; Werner, D.: "Multi-Material-Head". One tool for 3 technologies: Laserassisted thermoplastic tape placement, thermoset prepreg placement and dry-fiber placement. In: Proceedings of the 20th ICCM Conference. Kopenhagen, Dänemark, 19-24.07.2015, 8 S.

[8] N. N.: Conbility and Fraunhofer IPT Join Forces, Kunststoffe International, 2018. https://en.kunststoffe.de/a/product/conbility-and-fraunhofer-ipt-join-forces-246884 (Accessed 21.10.2021)

[9] N. N.: FILL Multilayer Produktbroschüre, FILL GmbH, 2019.

[10] N. N.: Tailored blank line with Fiberforge and Fibercon systems, Dieffenbacher GmbH, 2017.

[11] Kukla, C.; Peters, T.; Janssen, H.; Brecher, C.: Joining of Thermoplastic Tapes with Metal Alloys Utilizing Novel Laser Sources and Enhanced Process Control in a Tape Placement Process. In: Procedia CIRP. 66. Jg., 2017, P. 85-90.

[12] Weiler, T.; Striet, P.; Janssen, H.; Emonts, M.: Optical Modelling of VCSEL-Assisted Thermoplastic Tape Placement. In: Proceedings of the 17th European Conference on Composite Materials. ECCM17 - 17th European Conference on Composite Materials, 26-30th June 2016, Munich, Germany. Augsburg: MAI Carbon Cluster Management GmbH, 2016.

[13] Henne, F.; Ehard, S.; Kollmannsberger, A.; Hoeck, B.; Sause, M. G. R.; Obermeier, G.; Drechsler, K.: Thermoplastic in situ fiber placement for future solid rocket motor casings manufacturing. In: SAMPE SETEC, 2014.

[14] N. N.: Advanced Composites, Trelleborg Group, 2019. http://www.automateddynamics.com/article/thermoplastic-composite-basics/processingmethods/automated-fiber-placement (Accessed 21.10.2021)

[15] Miszalok, V.: Drucker und Plotter, 22.06.2009. 